New Developments in Sheep Production

Occasional Publication No. 14-British Society of Animal Production 1990

edited by C. F. R. Slade and T. L. J. Lawrence

\title{
SELECTION FOR IMPROVED CARCASS COMPOSITION IN TERMINAL SIRE SHEEP BREEDS
}

\author{
G. SIMM, W. S. DINGWALL, S. V. MURPHY and W. R. BROWN \\ Edinburgh School of Agriculture, West Mains Road, Edinburgh EH9 $3 J G$
}

\section{INTRODUCTION}

C onsumers generally prefer lamb much leaner than that actually produced. Farmers could respond, in the short term, to demand for leaner carcasses by slaughtering animals at lighter weights, stopping castration of males, manipulating the nutrient supply, or possibly by administration of growth promoting agents, although this latter course may well be unacceptable to consumers. But a preferable long-term response is to improve carcass leanness by genetic selection. Genetic improvement provides permanent, cost-effective and cumulative benefits in carcass composition.

A research project, using Suffolk sheep, was started at the Edinburgh School of Agriculture (ESA) in 1980 to examine the genetic potential for improving the lean content of lamb. In Britain almost $70 \%$ of the crossbred lambs slaughtered for meat production are sired by rams from the terminal sire breeds, yet these purebred flocks comprise only about $2 \%$ of all breeding ewes (Meat and Livestock Commission (MLC), 1988). Genetic improvement of this small group of animals can therefore have a large impact on the carcass quality of lambs slaughtered in the United Kingdom (UK).

The quickest route of genetic improvement is through breed substitution. But there are relatively small differences in lean growth rate amongst the most widely used breeds of terminal sires. Selection within these terminal sire breeds therefore offers a useful opportunity for reducing the fatness of lamb carcasses. The Suffolk breed was chosen for this research project because of its numerical importance as a terminal sire in the UK, but the results are relevant to all terminal sire breeds.

\section{OBJECTIVES AND DEVELOPMENT OF THE ESA SUFFOLK PROJECT}

The objectives of the ESA Suffolk Project are:

to evaluate techniques for assessing carcass composition in live sheep;

to apply the best available technique to the selection of genetically superior ram lambs and to measure the rate of genetic change in carcass leanness; and

to examine the performance of the crossbred progeny of high and low performing Suffolk rams, when their progeny are reared in extensive production systems.

Between 1980 and 1986 there were three phases in the development of the project:

\section{0 to 1983}

Establishment of the flock by purchase of cast-for-age Suffolk ewes, and hire or purchase of rams. Animals were taken from about 50 pedigree flocks.

\section{4 to 1985}

Testing a range of scanners for measuring carcass composition in live ram lambs, and developing a performance test regime for ram lambs.

\section{5 to 1986}

Developing a selection index for scoring ram lambs for the expected carcass lean content of their offspring.

The current phase of the project, started in 1986, involves index selection of rams for use in the pedigree flock, and comparisons with a control flock. High and low index rams are also being tested on crossbred ewes in an extensive production system.

\section{CURRENT FLOCK STRUCTURE}

The Suffolk flock now numbers some 220 breeding ewes. These ewes are split into two lines: 150 selection and 70 control ewes. The two lines are managed and fed identically, but bred differently. One of the problems of breeding experiments is distinguishing between changes in performance resulting from management, and those resulting from selection. One way of overcoming this is to have an unselected control flock which is managed identically to the selection flock. Differences in performance of the two flocks at any one time are then due solely to genetic differences between the animals.

The control flock is subdivided into six families. Ewe lambs born into any one family stay there for life, whilst 
ram lambs to be used for mating move on to the next family in a predetermined sequence, to minimize inbreeding. Control lambs with index scores closest to their family average are selected for breeding. This reduced the chance of unwanted dramatic increases or decreases in performance of the control line, due to chance-selection of specially good or bad control animals.

The selection flock is not divided into families, but mating groups are drawn up to avoid matings between close relatives. The six ram lambs with the highest index scores are selected for use in the selection flock (with the proviso that a maximum of two rams only can be taken from any one sire). Also, any selection or control ram ineligible for pedigree registration, or with physical defects, is not selected for breeding.

\section{DEVELOPMENT OF THE SELECTION INDEX}

Selection indexes are a valuable tool in selecting breeding stock, since they allow several different pieces of information on an animal (such as live weight and fatness) to be combined into a single score, on which the animals can be ranked. Two of the first steps in constructing an index are deciding on:

(1) the set of characteristics to be improved - the selection goal;

(2) the actual measurements taken on the animal as indicators of merit - the selection criteria.

The most appropriate selection goals for terminal sires are an increase of carcass lean weight and an increase of carcass lean proportion.

The measurements chosen to predict carcass lean weights in the ESA flock are live weight, ultrasonic fat depth, and ultrasonic muscle depth in the loin region.

The emphasis given to each of the measurements in an index depends on:

(1) the relative economic value of the individual characteristics to be improved;

(2) the scope for genetic improvement in these individual characteristics - - i.e. the heritability and the amount of variation present;

(3) the strength and direction of the genetic relationships between the characteristics to be

TABLE 1

Index scores for a high and a low performing ram lamb

Ultrasonic Ultrasonic muscle fat

Ram Age Liveweight depth depth identity (days) $\quad(\mathrm{kg}) \quad(\mathrm{mm}) \quad(\mathrm{mm}) \quad$ Index $\begin{array}{llllll}\text { C31 } & 150 & 77.9 & 34 \cdot 1 & 7.3 & 215\end{array}$

$\begin{array}{llllll}\text { C199 } & 150 & 56.8 & 28.4 & 10.6 & 25\end{array}$

TABLE 2

Ram lamb performance test results for 1989 (measurements at 150 days of age)

$\begin{array}{lccl} & \begin{array}{c}\text { Selection } \\ \text { Line }\end{array} & \begin{array}{c}\text { Control } \\ \text { Line }\end{array} & \text { Difference } \\ \begin{array}{l}\text { No. ram lambs tested } \\ \text { Average live weight }\end{array} & 71 & 38 & \\ \quad \text { (kg) } & 66.57 & 64.86 & +2.6 \% \\ \begin{array}{l}\text { Average muscle depth } \\ \text { (mm) }\end{array} & 30.47 & 28.68 & +6.2 \% \%^{* * *} \\ \begin{array}{l}\text { Average fat depth } \\ \text { (mm) }\end{array} & 7.04 & 7.57 & -7.0 \%^{*} \\ \text { Average index score } & 137 & 100 & +7.8 \dagger^{* * *}\end{array}$

$\dagger$ On unscaled index.

improved (carcass lean) and the actual measurements taken on the animals (live weight, fat depth and muscle depth).

The index derived for use in the ESA flock places roughly equal emphasis on live weight, muscle depth and fat depth (Simm and Dingwall, 1989). Live weight and muscle depth have positive weightings and fat depth has a negative weighting. The scores are scaled so that they range from about 20 for the poorest animals to about 220 for the best animals. Table 1 shows an example of one of the best and one of the worst ram lambs performance-tested in a single year.

Selection on the full index is expected to lead to annual increases of about $200 \mathrm{~g}$ carcass lean and about $70 \mathrm{~g}$ of carcass fat per annum. The expected gain in fat is a consequence of increased overall live-weight gain, but the proportion of fat is expected to decrease. Dropping muscle depth from the index would approximately double the annual increase in fat weight. Dropping both muscle depth and fat depth from the index - that is selection on live weight alone - is expected to lead to a further doubling of the amount of fat and an increase in fat proportion. This shows the benefits of including live-animal measurements of fat and muscle in the index.

\section{APPLICATION IN THE ESA SUFFOLK FLOCK}

Ram lambs tested in 1989 were the fourth crop sired by rams who themselves were selected on index score. Table 2 shows the average live weight, ultrasonic muscle depth, ultrasonic fat depth and index scores for selection and control line rams. On average, ram lambs from the selection line had higher live weights, significantly greater muscle depths and significantly lower fat depths than their control-line counterparts. Together, these led to higher index scores for selection-line lambs compared with control rams. These differences are encouraging at such an early stage in the selection programme. 


\section{APPLICATION IN THE SHEEP INDUSTRY}

Suffolk rams lambs in the ESA flock are performance tested on a high-energy/high-protein complete diet, to allow each animal to express its full potential for lean growth. This feeding policy facilitates food intake recording, but more importantly it is designed to maximize the variation in carcass composition between animals, thereby making selection of the best animals easier. In practice, the plane of nutrition of these animals and the growth rates achieved are similar to those in many pedigree Suffolk flocks producing ram lambs for sale. However, most crossbred lambs are reared on grass or forage crops. It is therefore important to know whether the best rams ranked on their index score at the end of the intensive performance test will also produce the best crossbred lambs in a commercial system.

To answer this question, teams of high and low ram lambs, ranked on their index score, were mated to crossbred ewes on the ESA farms. The experiment involved 400 Scottish Mule (Bluefaced Leicester $\times$ Scottish Blackface) ewes annually for 3 years. These ewes were mated to 11 'high' and 11 'low' indexing Suffolk ram lambs in each year, in individual mating paddocks. The crossbred progeny were reared on a grass-based finishing system, with weaning at about 14 weeks of age. Within each sire progeny group, lambs were allocated at random to one of three target slaughter live weights. These live weights were chosen to give carcass weights spanning the range of those produced in the industry (see Table 3). Lambs which failed to reach slaughter weights when grass declined in quality in the autumn were supplemented with concentrates. Lambs were weighed regularly between birth and slaughter. Following slaughter, approximately $20 \%$ of carcasses at each weight in each sire group were fully dissected (Simm, 1987). The remainder had a sample joint dissected (shoulder).

TABLE 3

Summary of the differences in predicted lean proportion and predicted total fat proportion between progeny of high and low index rams (adjusted to constant carcass weight $) \dagger$

Carcass weight $(\mathrm{kg})$

$16 \cdot \overbrace{19 \cdot 3 \quad 22 \cdot 3} \begin{gathered}\text { Average } \\ \text { difference }\end{gathered}$

Difference in predicted lean $(\mathrm{g} / \mathrm{kg})+6 \cdot 3+8 \cdot 0+8 \cdot 5^{*}+7 \cdot 6$

Difference in predicted total fat $(\mathrm{g} / \mathrm{kg}), \quad-9 \cdot 4^{*}-10 \cdot 7^{*}-10 \cdot 5^{*}-10 \cdot 2$

$\dagger$ From Brown (1989). Prediction based on shoulder joint dissections.
Table 3 summarizes dissection results from the 1st year of the trial involving Suffolk rams peformance tested in 1986, with crossbred lambs reared in 1987. On average, the progeny of high index sires had carcasses with $7.6 \mathrm{~g} / \mathrm{kg}$ more lean and $10.2 \mathrm{~g} / \mathrm{kg}$ less fat than carcasses from lambs sired by low index rams. At the same level of subcutaneous fatness, lambs from the high index sires were predicted to have carcasses about $0.75 \mathrm{~kg}$ heavier than those from the progeny of low index rams.

The scanning technique and selection index developed at the ESA have been taken up by MLC and offered as a service to pedigree breeders through their Sheepbreeder Scheme. In 1988 about 130 flocks of different breeds used the service, with over $6000 \mathrm{ram}$ lambs being scanned. In 1989 about 260 used the service, giving a rapid increase in the number of indexed rams available for pedigree breeders and commercial producers.

\section{CONCLUSIONS}

It is likely that returns from lamb production in future will depend, much more than at present, on producing leaner carcasses. There are several methods by which farmers can produce leaner lambs, and most progress will be made by combining these different methods. Genetic improvement is particularly attractive because it is permanent, cumulative and obtained relatively cheaply. Results from this project are providing valuable guidelines for terminal sire breeders and commercial producers on how to make most effective improvements in carcass leanness.

\section{ACKNOWLEDGEMENTS}

We are grateful for support, additional to the Department of Agriculture and Fisheries for Scotland core funding, from the MLC, the Suffolk Sheep Society and the Ministry of Agriculture, Fisheries and Food.

\section{REFERENCES}

Brown, W. R. 1989. A comparison of carcass composition of lambs from Suffolk sires selected for high and low lean growth index. B.Sc. Thesis, University of Edinburgh.

Meat and Livestock Commission. 1988. Sheep in Britain. Meat and Livestock Commission, Milton Keynes.

SIMM, G. 1987. Carcass evaluation in sheep breeding programmes. In New Techniques in Sheep Production, (ed. I. Fayez, M. Marai and J. B. Owen), pp. 125-144. Butterworths, London.

Simm, G. and Dingwall, W. S. 1989. Selection indices for lean meat production in sheep. Livestock Production Science 21: 223-233. 